\title{
Construction of Specialty Clusters under Strategic Orientation Choice: Hotel Industry or Its Culture?
}

\author{
Peng Zhao*, Xuan Ni, Shiqing Huang \\ Yinxing Hospitality Management College of CUIT \\ Chengdu, China, 611743
}

\begin{abstract}
This study aims to focus on the proper characteristic orientation of the hospitality college to promote its construction of specialty cluster. It shows that the orientation in the hotel industry or the highly-relevant leisure and tourism industry has neither attractiveness to cultivated junior hotel talents from the financial perspectives nor the effectiveness in construction of specialty cluster from the point of strategic flexibility. This paper abstracts the orientation toward good service out of hotel culture, which will increase strategic compatibility and dynamic adjustability among majors to drive the construction of specialty clusters in the hospitality college, so as to adapt to the new normal of the economy in China.
\end{abstract}

Keywords-strategic flexibility; strategic characteristic orientation; construction of specialty clusters; hotel cultures

\section{INTRODUCTION}

The characteristic orientation of hospitality management colleges is a strategic proposition, which affects the constructions of different disciplines and majors, as well as the college's whole sustainable development. But the positioning is often intuitively narrowed down as equal to the hotel industry itself or the highly-relevant leisure and tourism industries. The paper aims to analyze the connection between the financial characteristics and the dilemma of hospitality management talents' cultivation from the financial perspectives of return on assets (ROA) and operational risks. All the specialties form a strategic alliance to capture or create common value [1] under the characteristic orientation of the hotel college. On such a basis, the route for the flexibility expansion of the college's characteristic orientation and its benign influence on the construction of the specialty clusters are explored. Finally, this paper also provides policy recommendations on the construction of the specialty clusters based on the logic of the flexibility expansion of the hotel college's characteristic strategy.

\section{FINANCIAL CHARACTERISTIC AND DILEMMA OF TALENTS CULTIVATION IN HOTEL INDUSTRY}

\section{A. Hotel Industry in Equal ROA Curves}

ROA is a financial index to describe the capabilities of an industry or enterprise to acquire financial returns by using its tangible or intangible assets. The higher the value of the ROA, the stronger the capabilities of its wealth creation. ROA can be expressed as the product of profit margin and assets turnover. Different industries or enterprises with the same ROA value can be drawn on the same Equal ROA curve in spite of different portfolios of profit rate and assets turnover.

Citing Fig. 1 and Fig.2 [2] to investigate the ROA of the hotel industry by comparing it with other industries to obtain insights into the economic characteristics of this industry. Fig. 1 depicts equal ROA curves of different industries. The closer the curve is to (from) the original point, the weaker the wealth creation capability of a unit asset. It can be learned from Fig. 1 that the ROA of the hotel industry is only $3 \%$. Although its profit rate is a favorable $6 \%$, its assets turnover is so low, which pulls down the overall ROA of the industry. In Fig. 2, industries or enterprises of area A, B and C have different characteristics: area A has higher profit rate, but its assets turnover is restrained by its production capacity; area $\mathrm{C}$ has faster asset turnover, but its profit rate is limited by the fierce competition from outside; area $\mathrm{B}$ remains relatively intact by intense competitions and production capacities, so it demonstrates higher elasticity of the profit plan. The hotel industry lies in the area A due to its obvious capacity constraint, but its profit rate falling sharply because of the market turbulence caused by the slowed macroeconomic growth and the high-pressure tendency of anticorruption actions in China, even high-end hotels are no exception [3].

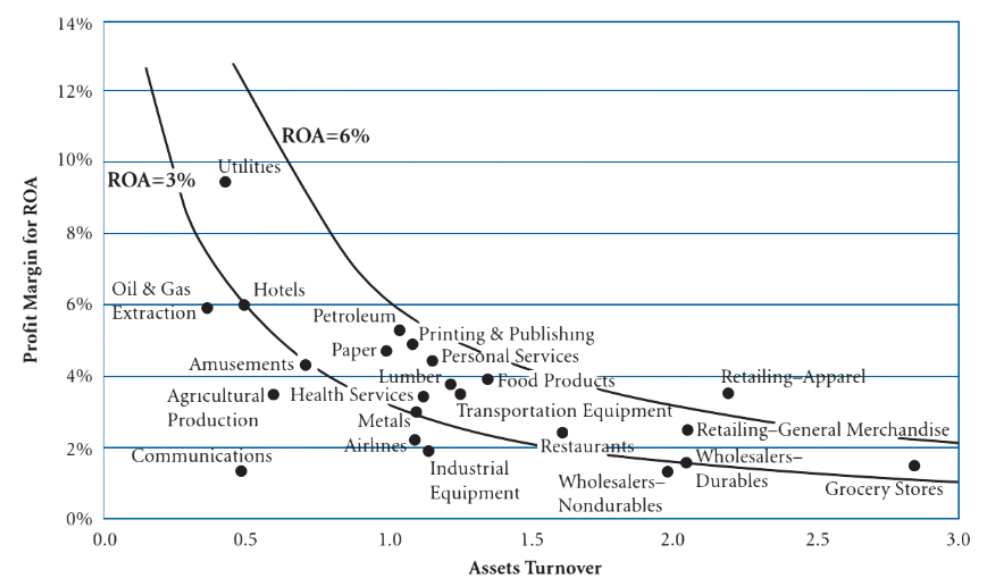

Fig. 1 Different Industries in the Equal ROA Lines 


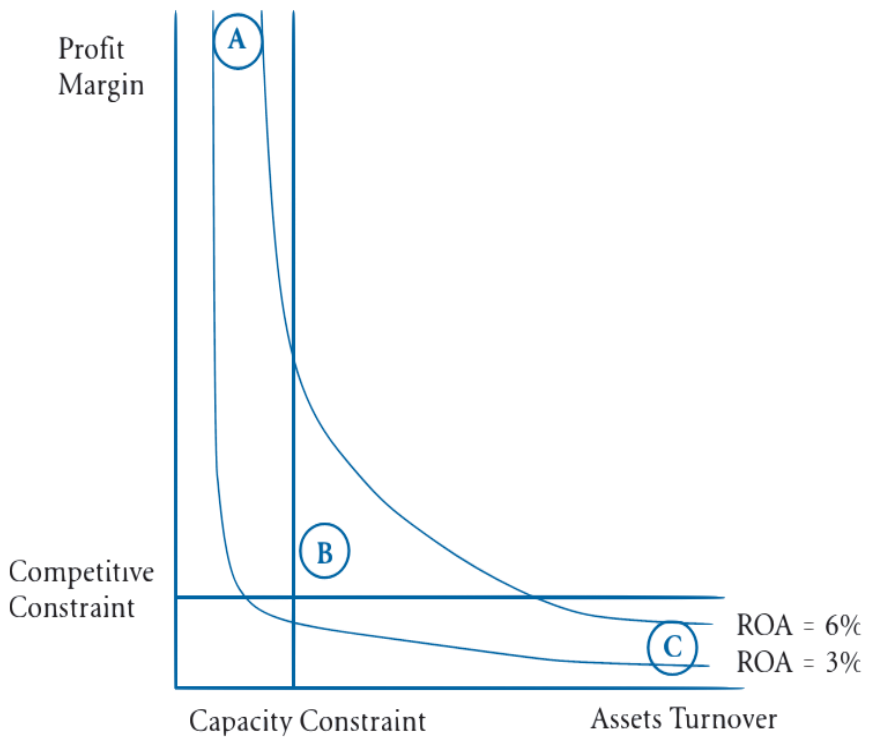

Fig. 2 Economic Factors Affecting the Profit Margin-Assets Turnover Mix

\section{B. Investments and Operational Risks in Hotel Industry}

Starred hotels require huge capital investments in the whole life circle from project planning, application approval, construction, luxury decoration, operation to go out of business, which results in the characteristics of capital intensiveness, high fixed costs, low variable costs, strict production capacity constraint, hard cost reimbursement from revenue, as well as high operational risks.

After investigating the internal profit and loss data of a fivestar hotel in Chengdu city in China season by season in the year 2016, the results show that the main method of turning its losses into profits is to slash labor wages. It indicates that, when the hotels come across revenue fluctuations caused by recession in macro economy, consumer preference volatility and other adverse factors, the hotels intended to utilize their stronger bargaining power of human resource cost to control the total costs to maintain their stated ROAs considering of the presence of high fixed costs incurred by heavy fixed assets investments. In all, the hotel industry has high operational risks and is short of means to effectively control costs.

\section{Dilemma on Talents Cultivation}

After continuous investigation into the average per capita employee salary, benefit and labor costs of the above-mentioned five-star hotel in Chengdu city in China in February 2016, it's not hard to find out in table I, which shows that the number of employees of the departments of Food and Beverages, and Housekeeping accounted for $62 \%$, but their income only accounted for $53 \%$, which reflects an even lower average per capita salary. The administration office stands for the hotel's highest management level, so its income looked reasonable. Although some departments such as the financial department had higher income, the difference compared to that in Food and Beverages, and Housekeeping departments was not considerable.

The investigation of the career path of the staff of the hotel from the lowest to the highest shows below: first-line sales department (Food and Beverages, Housekeeping, and Lobby), first-line department head, first-line department manager, firstline department assistant director, and general manager/director; second-line functional department staff ( Sales, Financial, Human Resources, and Engineering), secondline department head, second-line department manager, secondline assistant director, second-line department director, and general manager or director.

By linking the income and the career path, it is concluded that, in this industry, except that the managers and directors who have reasonable incomes, the incomes of the rest levels/ranks are not favorable and with minimum career development opportunities.

TABLE I. TABLE OF WAGE \& BENEFITS ETC. FOR DIFFERENT DEPARTMENTS

\begin{tabular}{|c|c|c|c|c|c|c|c|c|c|c|}
\hline Departments & $\begin{array}{c}\text { Administration } \\
\text { Office }\end{array}$ & Housekeeping & Lobby & $\begin{array}{c}\text { Food and } \\
\text { Beverages } \\
\end{array}$ & $\begin{array}{c}\text { Human } \\
\text { Resource }\end{array}$ & Security & Financial & Engineering & Sales & Sum \\
\hline $\begin{array}{l}\text { Number of } \\
\text { employees }\end{array}$ & 4 & 60 & 22 & 123 & 16 & 15 & 16 & 21 & 19 & 296 \\
\hline $\begin{array}{c}\text { Per capita } \\
\text { wage }(\mathrm{RMB})\end{array}$ & 16,838 & 2,631 & 3,079 & 3,162 & 2,780 & 3,423 & 5,721 & 3,575 & 4,512 & 3,480 \\
\hline $\begin{array}{c}\text { Per capita } \\
\text { benefit } \\
(\mathrm{RMB})\end{array}$ & 5,520 & 1,754 & 1,944 & 1,863 & 3,765 & 1,938 & 2,129 & 1,907 & 3,331 & 2,115 \\
\hline $\begin{array}{c}\text { Per capita } \\
\text { labor cost } \\
(\mathrm{RMB}) \\
\end{array}$ & 22,358 & 4,385 & 5,023 & 5,026 & 6,545 & 5,361 & 7,850 & 5,482 & 7,843 & 5,595 \\
\hline Percentage & $5.40 \%$ & $15.89 \%$ & $6.67 \%$ & $37.33 \%$ & $6.32 \%$ & $4.86 \%$ & $7.58 \%$ & $6.95 \%$ & $9.00 \%$ & $100.00 \%$ \\
\hline
\end{tabular}

Career identity is the base of proactivity and confidence in the construction of one's future career [4]. From the perspective of the hotel college, what are the implications of good cultivation? Cultivated students can be hired, retained, and promoted to a higher position is an intuitive criterion. From the above analysis, it results that graduates from hotel colleges keep entering into and going out of this industry rapidly, so the personnel training of hotel colleges is trapped in the dilemma of cultivation - low career identity - loss.

\section{REPOSITIONING THE CHARACTERISTIC OF HOSPITALITY MANAGEMENT COLLEGE}

\section{A. Strategic Defects on the Characteristic Orientation in the Hotel Industry Itself}

The characteristic of the hotel college oriented in the hotel industry or the highly-relevant leisure and tourism industry has multiple defects.

- Analyze from the above financial perspectives, the investment, operation and reward system traits of the hotel industry have led to the hotel talents cultivation 
trapped in the swamp of cultivation-low Career identity-loss. Without continuous career growth after graduation, without good reputation.

- Such an orientation fails to give enough logic rationality of other specialties set up in the hotel colleges such as computer specialty. This also embarrasses the enrollment propaganda work of other specialties in introducing their characteristics.

- Such an orientation fails to form a common core to synergize the construction of specialty clusters for the lack of the logic synergic point between all the seemingly unrelated specialties.

- Such an orientation reduces the efficiency of educational resource allocation. The idea of trying to push all the students who majored in Financial and Accounting in the hotel industry is very limited. Taking a hotel college in Chengdu city as an example, only less than $5 \%$ of the population of finance and accounting major obtained internships in the hotel industry. The low satisfaction rate of the internships, less than $1 \%$ retention rate in the short term and nearly $0 \%$ retention rate in the long term demonstrate the futility of hotel management courses opened in such a major.

- It fails to answer why such a characteristic orientation can be compatible with new specialties while eliminating old specialties, which is adverse for hotel colleges to implement transformation escalation of their specialty structures under the guidance of its strategy.

In a word, such an orientation undermines the intrinsic value excavation of the hotel industry or its relevant industries and impairs its abilities to encompass other extant specialties and to develop other new majors.

\section{B. Strategic Refining on Characteristic of Hospitality Management College}

Strategies represent the abstract and flexible aspects of an enterprise, including vision, mission, and value proposition, etc., under which the tangible aspects of specific tasks, strategic business units, and resource allocation are formed. Take Alibaba as an example. The vision of "To make easy to do business anywhere" doesn't belong to any particular industry, and the ecommerce platforms, payment platforms are all specific implementation routes of the vision.

Although the orientation in the hotel industry itself can be taken as a strategy, the mode is far from being able to dig into the implications of the hotel industry. Comparing to other industries, the hotel industry entails higher service awareness, spirit, skills, and experiences, etc. We can refine the strategy by locating the most abstract and universal value through the excavation of the "intangible" points concealed in the hotel culture, which can be the strategic factors to form the vision, mission and value proposition of hotel colleges.

\section{New Characteristic Orientation of Hospitality Management College}

Although there are different descriptions about hotel characteristic implications, the concept of high-quality services led by hotel culture has several advantages in the trend, because that can enrich the strategic flexibility [5] of hotel college characteristic orientation. It overcomes the multiple defects caused by the characteristic orientation in the hotel industry or the highly-relevant leisure and tourism industry. For example, the value proposition of high-quality service can not only penetrate every specialty opened in hotel colleges but also creates new growing space in the research of how to implement hotel characteristic quality services in various other specialties.

\section{STRATEGIC FLEXIBILITY OF NEW CHARACTERISTIC} ORIENTATION AND CONSTRUCTION OF SPECIALTY CLUSTERS

\section{A. Better Logic Support on Specialty Clusters Construction}

\section{1) Keep the old positioning advantage}

The value proposition of high-quality services led by hotel culture doesn't undermine the intrinsic nature of hotel management major as its trump card, on the contrary, it entices deep thoughts into the essence of hotel management characteristics, which will be integrated with the intrinsic natures of different specialties to forge cultural presentations by the implementation of quantitative behavioral indicators.

2) Strengthen the logical rationality of characteristic construction of other specialties

When hotel colleges refine the value proposition of highquality services from hotel industry as characteristics, every specialty launched in hotel colleges will have logical rationality with the construction aim of practical professional talents cultivation led by quality services. What's more, the college may get differentiated competitive advantages in majors such as financial and accounting, business administration over other colleges. For example, talents who have both quality services awareness, financial and accounting skills are suitable for any financial position in any industry, and will not be limited to those in the hotel industry.

\section{3) Improve professional integration}

To offer the hotel-related courses in non-hotel specialties has encountered boycott from both the designers of major cultivation program and non-hotel specialty students. Based on the narrowed understanding of hotel management, it is indeed hard to interpret why hotel courses have been provided for other majors such as financial management and information management specialties. But if viewed from the high-quality culture perspective, all specialties are related to hotel specialty through quality service culture. Besides, it's not advisable to copy hotel-related courses directly from hotel specialty to nonhotel specialties during the design of cultivation programs. On the contrary, we have to contemplate how to incorporate the quality service of hotel culture into different specialties, which will also lead to changes in course implementation forms. 


\section{B. Elasticity Improvement of Construction on Specialty Clusters}

\section{1) Extend more majors from existing industries}

If hotel college characteristic orientation can be determined as quality services led by hotel culture, based on the abovementioned financial analysis method, we can identify industries that have intersections with the hotel industry, which are of high ROA and requirements of quality services, and thus push the development of specialties into such intersectional industries.

2) Service requirements for innovation and entrepreneurship

The study of service scenarios of hotel culture-led specialties in the transitional economy will create new areas of college characteristic innovation and entrepreneurial projects. Through the exploration of the loopholes during the implementation of these projects, the construction of new specialty can be advanced, and college-wise win-win cooperation can also be conducted based on their respective capabilities.

\section{3) Facing emerging industries in the future}

Distinctive characteristics of services can moderate the effectiveness of the sources of competitive advantage [6]. Studies of service characteristics and demands in emerging industries in the future will provide cognitive tools to set up new specialties with foresight. It is different from expansion from existing industries, which means the following strategy, that faces the future emerging industry can be called the leading strategy. For example, what aspects can be impacted by artificial intelligence in the hotel industry? What's the main point of the future services industry?

\section{4) Dynamic adjustment on specialties}

Specialties setup must be dynamically adjusted according to the changing of the macro economy, technology, social culture, and other factors. A hotel college can always adjust its specialty structure from the standpoint of integration of high-quality services into specific non-hotel specialties. For example, the pension industry will arise for the changes in the population composition in the future, which can be integrated deeply with the quality services led by hotel culture. To implement the integration, it is possible to consider the joint application of a new specialty with colleges with special advantages in nursing care.

\section{CONCLUSION AND POLICY SUGGESTION}

\section{A. Conclusion}

From the financial perspectives of Return on Assets (ROA) and operational risks, the paper analyzed multiple defects of the characteristic orientation of hotel colleges in the hotel industry or the highly-relevant leisure and tourism industry. The paper also explored why the migration of the hotel college characteristic into high-quality services led by hotel culture would provide more strategic flexibility and benign influence from several perspectives, such as: extending more majors from existing industries, service requirements for innovation and entrepreneurship, facing emerging industries in the future, dynamic adjustment on specialties.

\section{B. Policy Suggestion}

1) Establish sniffer institute on specialties

By utilizing the flexible system of independent colleges [7], from the integration possibilities and degrees of quality services led by hotel culture with current and future industries, hotel colleges can establish sniffer institutes on specialties to enhance the study of changes in trend of current specialties, and the feasibility of setting up new specialties, with periodic submission of research reports.

2) Innovation and entrepreneurship incubation

The integration of quality services led by hotel culture with current and future industries will surely entail numerous opportunities for innovation and entrepreneurship, which can fit into all levels of innovation and entrepreneurial contests and select high-quality projects for incubation. Successfully incubated projects can be the new investment direction of the hotel colleges.

\section{REFERENCES}

[1] O'Dwyer, M. and A. Gilmore, Value and alliance capability and the formation of strategic alliances in SMEs: The impact of customer orientation and resource optimization. Journal of Business Research, 2018. 87: pp. 58-68.

[2] James Wahlen, Stephen Baginski, Mark Bradshaw, Financial Reporting, Financial Statement Analysis and Valuation, 8e, Cengage Learning, 2015, pp.269-275.

[3] He, Z., Corruption and anti-corruption in reform China. Communist and Post-Communist Studies, 2000. 33(2): pp. 243-270.

[4] Santisi, G., et al., Psychological resources, satisfaction, and career identity in the work transition: an outlook on Sicilian college students. Psychology Research \& Behavior Management, 2018. 11: p. 187.

[5] Brozovic, D., Strategic Flexibility: A Review of the Literature: Strategic Flexibility. International Journal of Management Reviews, 2018. 20(1).

[6] Bharadwaj, S.G., J. Fahy, and P.R. Varadarajan, Sustainable Competitive Advantage in Service Industries: a Conceptual Model and Research Propositions. Journal of Marketing, 2015. 57(4): pp. 83-99.

[7] Mingkun Que, On the Mixed Ownership Model of the Affiliated College. Journal of Higher Education, 2017.38(3): pp. 65-71 (In Chinese) 